as well as high consistency between wishes specified in the advance directive and treatment decisions at the end of life. $\mathrm{AD}$ information and course of hospitalisation were compared for decedents (2005-2010) before and after Respecting Choices was implemented. Our results $(n=732)$ showed that Respecting Choices did have a statistically significant effect on increasing $A D$ prevalence $(p=.015)$. The increase in AD prevalence for Whites as a result of Respecting Choices was marginal (46.7\% to $47.9 \%$ ), yet the increase for racial and ethnic minorities was substantial ( $27 \%$ to $39.2 \%) ;(p=.100)$. The consistency of wishes expressed in the $\mathrm{AD}$ and the medical orders written to restrict life-sustaining treatment were relatively high for all treatment decisions (73.9\%-96\% consistent), regardless of race. Beyond prevalence and consistency, our study also looked at the utilisation of ADs, by assessing the number of days prior to death medical orders were written to restrict lifesustaining treatments, as a result of Respecting Choices and ADs, stratified by race.

\title{
Minorities/Disabilities
}

\section{IMPROVING ADVANCE CARE PLANNING IN A RACIALLY AND ETHNICALLY DIVERSE COMMUNITY}

K.Pecanac ${ }^{* *}$; M. Repenshek ${ }^{2}$ University of Wisconsin, Madison; ${ }^{2}$ Columbia St. Mary's Hospital, Milwaukee

10.1136/bmjspcare-2012-000250.37

Respecting Choices, a program developed to improve advance directive (AD) prevalence and utilisation, has been very successful in the La Crosse County, Wisconsin community. However, La Crosse County is a racially and ethnically homogenous community, and little is known about whether Respecting Choices is equally effective in racially and ethnically diverse communities. The purpose of this study was to see if implementing the Respecting Choices program in a racially and ethnically diverse community in the United States would produce the same success of increased prevalence of advance directives 